\title{
Continuous irradiation with a 633-nm light-emitting diode exerts an anti-aging effect on human skin cells
}

\author{
HAK SUN KIM ${ }^{1}$, WON SANG PARK ${ }^{1}$, JONG-IN BAEK ${ }^{1}$, BO-SUB LEE ${ }^{2}$, DAE SUNG YOO ${ }^{2}$ and SI JUN PARK ${ }^{2}$ \\ ${ }^{1}$ Samsung Display Co., Ltd., Yongin, Gyeonggi-do 446-811; ${ }^{2}$ R\&D Center, ACT Co., Ltd., \\ Suwon, Gyeonggi-do 443-734, Republic of Korea
}

Received April 14, 2014; Accepted November 24, 2014

DOI: $10.3892 / \mathrm{ijmm} .2014 .2030$

\begin{abstract}
Accumulating evidence has indicated that the light source emitted from light-emitting diode (LED) has a potential anti-aging effect on human skin. Studies using single and interval LED irradiation have documented such effects; however, to the best of our knowledge, the anti-aging effects of continuous LED irradiation have not yet been investigated. In the present study, we demonstrated that continuous irradiation with a $633 \pm 3-n m$ LED exerted anti-aging effects in both in vitro and ex vivo experiments. More specifically, irradiation with a 633-nm LED for 2 days increased the synthesis of type 1 procollagen and decreased the expression of matrix metalloproteinase $(M M P) 1$ and $M M P 2$ in skin fibroblasts. In addition, irradiation with a 633-nm LED decreased the expression levels of inflammatory genes, such has cyclooxygenase-2 (COX-2), and interleukin-1- $\alpha(I L-1 \alpha)$ in keratinocytes. Furthermore, a 14-day LED irradiation moderately increased keratinocyte proliferation. Using human skin explants, we confirmed the safety of this 633-nm LED irradiation, which resulted in unaltered morphology and allergy-free potential in human tissue. Overall, these data provide insight into the anti-aging effects of continuous LED irradiation on human skin.
\end{abstract}

\section{Introduction}

As the aging population continuously increases, the age-related dermatological concerns are continuously addressed by the cosmetic and medical industries (1). Skin aging is a multisystem degenerative process, which is characterized by the loss of structural integrity and physiological function by both intrinsic and extrinsic determinants (2). Intrinsic skin aging is caused by genetic determinants; therefore, this mechanism is an inevitable natural consequence of physiological changes in the absence of altered genetic information (3). Extrinsic skin aging, on the

Correspondence to: Dr Si Jun Park, R\&D Center, ACT Co., Ltd., 102-201, Digital Empire II, 486 Sin-dong, Youngtong-gu, Suwon, Gyeonggi-do 443-734, Republic of Korea

E-mail: coolsijun@actcos.com

Key words: light-emitting diode, $633 \mathrm{~nm}$ wavelength, skin, anti-aging, irradiation other hand, is caused by extracellular factors, such as ultraviolet radiation, pollutants and nicotine; therefore, this type of aging is controllable as individuals can avoid these age-inducing factors (3). Among the signs of skin aging, wrinkling is the primary characteristic, which is induced by decreasing collagen and increasing collagenase production (4). Collagen, which is the most abundant protein in connective tissue in mammals, contributes to firmness and is thus vital for skin elasticity. The most common type of collagen in the skin is type 1 collagen, which comprises $>90 \%$ of the collagen in the body (5). Type 1 collagen is composed of two $\alpha 1(\mathrm{I})$ chains and one $\alpha 2(\mathrm{I})$ chain, which are encoded by the COL1A1 and COL1A2 genes, respectively (5). The synthesis of type 1 collagen is transcriptionally regulated in skin fibroblast cells, and UV-induced photoaging involves the downregulation of COL1A1 and COL1A2 and the consequent loss of collagen that induces fine wrinkles. In addition, the level of collagen is regulated by its proteolytic enzymes, matrix metalloproteinases (MMPs). Studies have demonstrated that skin aging induced by UV exposure is mediated by the upregulation of MMP1 expression $(6,24)$. Therefore, several cosmetic products, including epigallocatechin-3-gallate (EGCG), exert their anti-aging effects through the upregulation of collagen synthesis and the downregulation of MMPs in skin fibroblasts (7).

In addition to the application of phytochemicals as potential anti-aging agents, several light sources have been investigated for their anti-aging effects on skin cells and tissues. Intense pulsed light (IPL) at wavelengths between 570 and $615 \mathrm{~nm}$ have proven to be an effective treatment for refractory melasma in Asian patients with minimal side-effects (8). In addition Moreover, 530-nm IPL may improve inflammatory acne through the downregulation of tumor necrosis factor- $\alpha$ (TNF- $\alpha)$ (9). Furthermore, studies have demonstrated that light-emitting diode (LED) irradiation at wavelengths of 590, 630, 633 and $660 \mathrm{~nm}$ is effective in photorejuvenation in vitro and in clinical studies in vivo (10-15). Following irradiation with a 590-nm LED, type 1 collagen levels have been shown to increase, while MMP1 levels have been shown to decrease (12). In a previous study, irradiation with a 660-nm LED was found to modulate the levels of type 1 procollagen and MMP1 by 31 and $-18 \%$, respectively (10). In another study, the irradiation of fibroblasts with a combination of a 630- and 830-nm LED or a 660- and 850-nm LED also increased collagen levels (14). These clinical and in vitro studies, however, examined the effects of single 
or interval LED irradiation, as opposed to continuous LED irradiation. Of note, to the best of our knowledge, the effects of continuous LED irradiation on skin cells and tissues have not yet been thoroughly investigated. To overcome experimental limitations, we manufactured a new cell culture incubator containing a 633-nm LED device and used this equipment to investigate the effects of continuous LED irradiation on skin fibroblasts and keratinocytes. Furthermore, for confirmation of the effects of continuous LED irradiation on human skin tissue, we cultured human skin explants in the LED incubator. We also investigated the safety of continuous LED irradiation at $633 \mathrm{~nm}$ by examining the levels of inflammatory genes in vitro and the migration rate of Langerhans cells to the dermis in tissues.

\section{Materials and methods}

Cell lines and chemicals. CCD-986sk normal human skin fibroblasts and $\mathrm{HaCaT}$ keratinocytes were purchased from the American Type Culture Collection (ATCC; Manassas, VA, USA) and Cell Lines Service (DKFZ, Eppelheim, Germany), respectively. The CCD-986sk and HaCaT cells were grown in Dulbecco's modified Eagle's medium (DMEM supplemented with $10 \%$ fetal bovine serum, $100 \mathrm{U} / \mathrm{ml}$ penicillin and $100 \mu \mathrm{g} /$ $\mathrm{ml}$ streptomycin (all from Gibco Life Technologies, Grand Island, NY, USA). The 1-chloro-2,4-dinitrobenzene (DNCB) and the Dermatophagoides farinae body extract, which are agents used to induce an allergic reaction, were purchased from Sigma-Aldrich (St. Louis, MO, USA) and Biostir Inc. (Kobe, Japan), respectively.

Light source. The LED device, which emits a 633-nm wavelength, was provided by Samsung Electronics Co., Ltd. (Seoul, Korea). The spectral characteristics of the LED device were as follows: the peak wavelength was $633 \pm 3 \mathrm{~nm}$ and the full width at half maximum was approximately $20 \mathrm{~nm}$. The effective irradiance values on the cell plates were adjusted to be 5 and $47.5 \mu \mathrm{W} / \mathrm{cm}^{2}$. For comparison, lighting devices with organic LEDs with the same spectral characteristics were prepared. Due to the high humidity (almost 100\%) in the cell culture incubator, we sprayed a silicone varnish on the lighting devices to provide waterproofing and insulation. Cells subjected to no irradiation were used as controls.

Cell viability assay. The cytotoxic effects of the LED lights on the CCD-986sk and HaCaT cells were evaluated using a water-soluble tetrazolium salt (WST-1) assay (EZ-Cytox Cell Viability Assay kit; Itsbio, Seoul, Korea). WST-1 solution (1/10 culture medium volume) was added to the cultures, and the cells were incubated at $37^{\circ} \mathrm{C}$ for $0.5 \mathrm{~h}$. Cell viability was determined according to the absorbance at $450 \mathrm{~nm}$ using an iMark $^{\mathrm{TM}}$ microplate reader (Bio-Rad, Hercules, CA, USA). All results are presented as the mean percentage \pm standard deviation (SD) of 3 independent experiments.

Enzyme-linked immunosorbent assay (ELISA) for procollagen type I. The ELISA assay for procollagen type 1 was performed using the Procollagen Type I C-Peptide (PIP) EIA kit (Clontech Laboratories Inc./Takara Bio Inc., Otsu, Japan) according to the manufacturer's instructions. Briefly, the CCD-986sk cells were irradiated with a low $\left(5 \mu \mathrm{W} / \mathrm{cm}^{2}\right)$ and high $(47.5 \mu \mathrm{W} /$ $\mathrm{cm}^{2}$ ) intensity LED for 24 and $72 \mathrm{~h}$. Following irradiation, the cell supernatants were collected. The antibody-peroxidase (POD) conjugate solution (Clontech Laboratories Inc./Takara Bio Inc.) was transferred to a well of an anti-PIP monoclonal antibody-coated plate (Clontech Laboratories Inc./Takara Bio Inc.), and the supernatant was subsequently added. The mixed samples were incubated. After discarding the well contents, the wells were washed with wash buffer (Clontech Laboratories Inc./Takara Bio Inc.). Substrate solution (Clontech Laboratories Inc./Takara Bio Inc.) was then added to each well, and the plates were incubated at room temperature for $15 \mathrm{~min}$. Stop solution (Clontech Laboratories Inc./Takara Bio Inc.) was added, and the absorbance at $450 \mathrm{~nm}$ was measured using an iMark microplate reader. All results are presented as the mean percentage \pm standard deviation (SD) of 3 independent experiments. A p-value $<0.01$, as determined by the Student's t-test, was considered to indicate a statistically significant difference.

Isolation of total RNA and quantitative reverse transcription PCR (RT-qPCR). After 24 and $72 \mathrm{~h}$ of irradiation, total RNA was isolated using TRIzol reagent (Life Technologies) according to the manufacturer's instructions. The purity and concentration of the RNA was evaluated based on the optical density (OD) at $260 \mathrm{~nm}$ and the OD 260/230 and 260/280 ratios using MaestroNano ${ }^{\circledR}$, a micro-volume spectrophotometer (Maestrogen, Las Vegas, NV, USA). cDNA was then synthesized using a SuperScript ${ }^{\circledR}$ III First-Strand Synthesis System for RT-PCR (Life Technologies). Quantitative (realtime) PCR was performed using SYBR ${ }^{\circledR}$-Green PCR Master Mix and the SYBR ${ }^{\circledR}$-Green RT-PCR Reagents kit (Life Technologies) and analyzed using Line-Gene $\mathrm{K}$ software (Bioer Technology Co. Ltd., Hangzhou, China). The $\mathrm{C}_{\mathrm{T}}$ value for each gene was normalized to GAPDH. The $2^{-\triangle \triangle C T}$ method was used to calculate the relative expression levels of each gene. The primers used for RT-qPCR are presented in Table I.

Human skin explant-based assay. For analysis of the safety of low $\left(5 \mu \mathrm{W} / \mathrm{cm}^{2}\right)$ and high $\left(47.5 \mu \mathrm{W} / \mathrm{cm}^{2}\right)$ intensity LED irradiation on human skin, we utilized the expertise of BIO-EC Laboratory (Longjumeau, France). Prior to this study, the BIO-EC Laboratory submitted these procedures to the Ethics Committee for the appropriate French geographic sector (Hôpital du Kremelin-Bicêtre, Le Kremelin Bicêtre, France) via the website of the French Ministry of Health. Furthermore, BIO-EC had previously developed a professional relationship with clinics and hospitals and was thus allowed to use human skin explants that were not specifically excised for experimentation in accordance with all applicable ethical principles.

A total of 33 human skin explants obtained from an abdominoplasty from a 45 -year-old female were used. The diameter of each explant was $\sim 10 \mathrm{~mm}$. The explants were preserved in BEM medium (BIO-EC's Explant Medium batch 060208) at $37^{\circ} \mathrm{C}$ in a moist atmosphere containing $5 \% \mathrm{CO}_{2}$ for $12 \mathrm{~h}$ before the study was initiated. The DNCB solution $(0.0062 \%)$ and the Dermatophagoides farinae body extract $\left(10 \mathrm{mg} / \mathrm{cm}^{2}\right)$ were applied topically to each explant for 1 or 2 days. Other skin explants were irradiated with low $\left(5 \mu \mathrm{W} / \mathrm{cm}^{2}\right)$ and high $\left(47.5 \mu \mathrm{W} / \mathrm{cm}^{2}\right)$ intensity LED for 1 or 2 days. After the 1- or 2-day applications, the skin explants were fixed in Bouin's solution (30\% formaldehyde, $5 \%$ acetic acid, $4 \%$ methyl-alcohol 
Table I. Sequences of the specific primers used in this study.

\begin{tabular}{|c|c|c|}
\hline Gene & Direction & Primer sequences \\
\hline COL1A1 & $\begin{array}{l}\mathrm{F} \\
\mathrm{R}\end{array}$ & $\begin{array}{l}\text { 5'-AGCCAGCAGATCGAGAACAT-3' } \\
\text { 5'-TCTTGTCCTTGGGGTTCTTG-3' }\end{array}$ \\
\hline$M M P 1$ & $\begin{array}{l}\mathrm{F} \\
\mathrm{R}\end{array}$ & $\begin{array}{l}\text { 5'-GATGTGGAGTGCCTGATGTG-3' } \\
\text { 5'-TGCTTGACCCTCAGAGACCT-3' }\end{array}$ \\
\hline$M M P 2$ & $\begin{array}{l}\mathrm{F} \\
\mathrm{R}\end{array}$ & $\begin{array}{l}\text { 5'-GTGCTGAAGGACACACTAAAGAAGA-3' } \\
\text { 5'-TTGCCATCCTTCTCAAAGTTGTAGG-3' }\end{array}$ \\
\hline$T N F-\alpha$ & $\begin{array}{l}\mathrm{F} \\
\mathrm{R}\end{array}$ & $\begin{array}{l}\text { 5'-GACCTCTCTCTAATCAGCCC-3' } \\
\text { 5'-CAAAGTAGACCTGCCCAGACC-5' }\end{array}$ \\
\hline$C O X-2$ & $\begin{array}{l}\mathrm{F} \\
\mathrm{R}\end{array}$ & $\begin{array}{l}\text { 5'-TTCAAATGAGATTGTGGAAAAATTGCT-3' } \\
\text { 5'-AGATCATCTCTGCCTGAGTATCTT-3' }\end{array}$ \\
\hline$I L-1 a$ & $\begin{array}{l}\mathrm{F} \\
\mathrm{R}\end{array}$ & $\begin{array}{l}\text { 5'-GTCTCTGAATCAGAAATCCTTCTATC-3' } \\
\text { 5'-CATGTCAAATTTCACTGCTTCATCC-3' }\end{array}$ \\
\hline GAPDH & $\begin{array}{l}\mathrm{F} \\
\mathrm{R}\end{array}$ & $\begin{array}{l}\text { 5'-CGCTCTCTGCTCCTCCTGTT-3' } \\
\text { 5'-CCATGGTGTCTGAGCGATGT-3' }\end{array}$ \\
\hline
\end{tabular}

COL1A1, collagen, type I, alpha 1; MMP, matrix metalloproteinase; TNF- $\alpha$, tumor necrosis factor- $\alpha$; COX-2, cyclooxygenase- $2 ; I L-1 \alpha$, interleukin- $1 \alpha ; \mathrm{F}$, forward; $\mathrm{R}$, reverse.

and $1 \%$ picric acid; BIO-EC Laboratory). Subsequently, a dehydration and impregnation process was used for the processing of the explants. During this process, water was progressively removed and replaced with ethanol using a $70 \%$ ethanol solution followed by a $95 \%$ ethanol solution. Ethanol was then replaced by butanol, and the explants were finally immersed in a bath containing paraffin at $56^{\circ} \mathrm{C}$. This 3 -day process included 3 baths of $70 \%$ ethanol, 3 baths of $95 \%$ ethanol, 5 baths of butanol and 2 baths of paraffin. After the preparation, the explants were placed in blocks with a Leica EG 1160 coating station (Leica Microsystems, Nussloch, Germany), and 5- $\mu \mathrm{m}$-thick slices were prepared using a Minot-type microtome (Leica 2125; Leica Microsystems) and pressed onto superfrosted silanized glass slides. Microscopic observations were performed using an optical microscope (Leica-type DLMB microscope; Leica Microsystems) with a x20 objective. Photomicrographs were performed captured with a CCD Sony DXC-390P camera (Sony, Tokio Tokyo, Japan) and stored with Leica IM1000 data archiving software (Leica Microsystems). The observations of general morphology were performed on paraffin slices dyed with Masson's trichrome, Goldner variant. As this study resulted in only observational and descriptive data, no statistical analysis was appropriate or feasible.

Analysis of CDla-positive Langerhans cells. The DNCB solution $(0.0062 \%)$, the Dermatophagoides farinae body extract $\left(10 \mathrm{mg} / \mathrm{cm}^{2}\right)$, and low $\left(5 \mu \mathrm{W} / \mathrm{cm}^{2}\right)$ and high $\left(47.5 \mu \mathrm{W} / \mathrm{cm}^{2}\right)$ intensity LED irradiation were applied topically to each explant for 1 or 2 days as described above. After the samples were fixed and paraffinized, the sections were immunostained using anti-CD1a 1gG antibody (Cat, no. sc-5265; Santa Cruz Biotechnology, Santa Cruz, CA, USA). The CD1a-positive cells were enumerated lengthways for each explant, and the number was extrapolated to the epidermic length in centimeters.

\section{Results}

Characterization of LED-induced cytotoxicity in human skin fibroblasts and keratinocytes. We first sought to determine whether LED irradiation at a wavelength of $633 \mathrm{~nm}$ affects the viability of human skin cells. CCD-986sk normal human skin fibroblasts and $\mathrm{HaCaT}$ keratinocytes were irradiated with low $\left(5 \mu \mathrm{W} / \mathrm{cm}^{2}\right)$ and high $\left(47.5 \mu \mathrm{W} / \mathrm{cm}^{2}\right)$ intensity LED at $633 \mathrm{~nm}$ for 24 and $72 \mathrm{~h}$. As shown in Fig. 1A, the exposure of the CCD-986sk cells to low intensity LED irradiation for 24 and $72 \mathrm{~h}$ induced no cytotoxicity, according to the results of the WST-1 assay. We also found that high intensity LED irradiation did not cause any cytotoxicity to these cells (Fig. 1B). We then examined the LED-mediated cytotoxic effects on human HaCaT keratinocytes. The HaCaT cells were irradiated with low and high intensity LED at $633 \mathrm{~nm}$ for 24 and $72 \mathrm{~h}$. LED irradiation-mediated cytotoxicity was not observed in the HaCaT cells irradiated with low and high intensity LED (Fig. 1C and D). Of note, both low and high intensity LED irradiation slightly increased the viability of the $\mathrm{HaCaT}$ cells. More specifically, high intensity LED irradiation for 24 and $72 \mathrm{~h}$ increased the viability of the cells to $102.9 \pm 1.2 \%$ and $105.7 \pm 1.3 \%$ of the control value $(n=3)$, respectively. These results demonstrate that 633-nm LED irradiation does not induce any cytotoxic effects on CCD-986sk human skin fibroblasts and HaCaT keratinocytes.

Characterization of the LED irradiation-induced production of procollagen in human skin fibroblasts. We then examined whether irradiation with a 633-nm LED increases the production of procollagen type 1 , which is synthesized and secreted by skin fibroblasts and provides strength and elasticity in skin tissue. CCD-986sk normal human skin fibroblasts were exposed to low and high intensity 633-nm LED irradiation for 
A
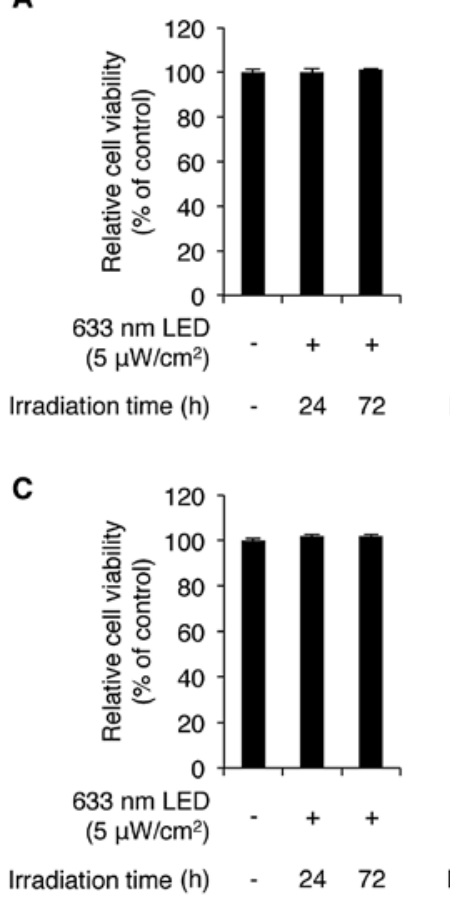

A

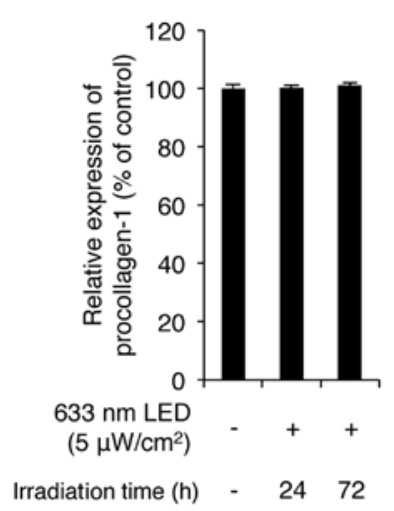

B

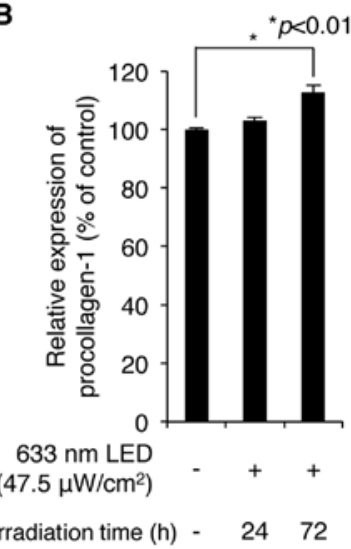

Figure 2. Irradiation with a 633-nm LED induces the production of procollagen type 1 in CCD986-sk human fibroblasts. (A) Low intensity LED has little effect on the production of procollagen-1 in CCD986-sk human fibroblasts. Cells were seeded in 24-well culture dishes and irradiated with $5 \mu \mathrm{W} / \mathrm{cm}^{2} \mathrm{LED}$ for 24 and $72 \mathrm{~h}$. After irradiation, the medium was collected, and the amount of secreted procollagen type 1 was measured using an ELISA assay. Results are presented as the mean percentage \pm SD from 3 independent experiments. (B) High intensity LED increases the production of procollagen type 1 in CCD986-sk cells. Cells were irradiated with $47.5 \mu \mathrm{W} / \mathrm{cm}^{2}$ LED for 24 and $72 \mathrm{~h}$, and then the amount of secreted procollagen type 1 was determined using an ELISA assay. Data are presented as the mean percentage \pm SD from 3 independent experiments. ${ }^{*}$ < $<0.01$ compared with the controls (no treatment).

Figure 1. Irradiation with a 633-nm LED does not induce cytotoxic effects CCD986-sk human fibroblasts and HaCaT keratinocytes. (A) Low intensity LED irradiation is not cytotoxic to CCD986-sk human fibroblasts. Cells were seeded in 96-well culture dishes and irradiated with $5 \mu \mathrm{W} / \mathrm{cm}^{2} \mathrm{LED}$ for 24 and $72 \mathrm{~h}$. After irradiation, cell viability was measured by WST-1 assay. (B) High intensity LED irradiation does not affect the viability of CCD986-sk cells Cells were irradiated with $47.5 \mu \mathrm{W} / \mathrm{cm}^{2}$ LED for 24 and $72 \mathrm{~h}$, and then the WST-1 assay was performed to determine cell viability. (C) Low intensity LED irradiation is not cytotoxic to HaCaT human keratinocytes. Cells were seeded and irradiated with $5 \mu \mathrm{W} / \mathrm{cm}^{2}$ LED for 24 and $72 \mathrm{~h}$. After irradiation, the viability of cells was determined by WST-1 assay. (D) High intensity LED irradiation induces no change in the viability of HaCaT cells. Cells were irradiated with $47.5 \mu \mathrm{W} / \mathrm{cm}^{2}$ LED for 24 and $72 \mathrm{~h}$, and then the WST-1 assay was performed to determine cell viability. All data are presented as the means \pm SD from 3 independent experiments.

24 and $72 \mathrm{~h}$. The levels of procollagen type 1 in the cultured cell supernatants were analyzed by ELISA using a procollagen type 1-specific antibody. The exposure of the cell cultures to LED irradiation ranging from 5 to $47.5 \mu \mathrm{W} / \mathrm{cm}^{2}$ for 24 and $72 \mathrm{~h}$ increased the production of procollagen type 1 in an intensityand exposure time-dependent manner (Fig. 2A and B). Although LED irradiation at $5 \mu \mathrm{W} / \mathrm{cm}^{2}$ slightly increased the production of procollagen type 1, maximal production was obtained at an intensity of $47.5 \mu \mathrm{W} / \mathrm{cm}^{2}$ for $72 \mathrm{~h}$. These conditions increased the levels of procollagen type 1 to $112.8 \pm 2.3 \%$ of the control value $(n=3)$. These results demonstrate that a relatively high intensity of irradiation (633-nm LED) positively regulates the production of procollagen type 1 in human skin fibroblasts.

LED irradiation downregulates the expression levels of MMP1 and MMP2 in human skin fibroblasts. Subsequently, we wished to determine whether LED irradiation regulates the expression levels of COL1A1, MMP1 and MMP2. Following exposure of the CCD-986sk human skin fibroblasts to low $\left(5 \mu \mathrm{W} / \mathrm{cm}^{2}\right)$ and high $\left(47.5 \mu \mathrm{W} / \mathrm{cm}^{2}\right)$ intensity $633-\mathrm{nm}$ LED irradiation, the expression of COL1A1, MMP1 and MMP2 was analyzed using RT-qPCR with specific primers for each

mRNA sequence. As shown in Fig. 3A, exposure of the cells to low intensity LED irradiation at $633 \mathrm{~nm}$ for 24 and $72 \mathrm{~h}$ did not result in the altered mRNA expression of COL1A1, MMPI and $M M P 2$; however, high intensity LED irradiation at $633 \mathrm{~nm}$ significantly downregulated the expression of $M M P 1$ and $M M P 2$, but not that of COL1A1 (Fig. 3B). Notably, following 633-nm LED irradiation at $47.5 \mu \mathrm{W} / \mathrm{cm}^{2}$ for $24 \mathrm{~h}$, the expression levels of $M M P 1$ decreased to $96.9 \pm 0.6 \%$ of the control and those for $M M P 2$ decreased to $90.1 \pm 0.7 \%$ of the control; following LED irradiation for $72 \mathrm{~h}$, the expression levels of $M M P 1$ decreased to $74.0 \pm 0.3 \%$ of the control and those for $M M P 2$ decreased to $70.6 \pm 1.9 \%$ of the control (Fig. 3B). However, the expression level of COL1Al was not altered by low and high intensity LED irradiation in CCD-986sk human skin fibroblasts. These results indicate that 633-nm LED irradiation induces the downregulation of $M M P 1$ and $M M P 2$, but does not affect COLIA1 expression in human skin fibroblasts.

LED irradiation downregulates the expression of genes related to the inflammatory response in human keratinocytes. We then investigated whether LED irradiation affects skin inflammation. HaCaT normal human keratinocytes were irradiated with low $\left(5 \mu \mathrm{W} / \mathrm{cm}^{2}\right)$ and high $\left(47.5 \mu \mathrm{W} / \mathrm{cm}^{2}\right)$ intensity LED at $633 \mathrm{~nm}$, and the effects of this irradiation on skin inflammation were analyzed by determining the expression levels of inflammation-related genes, such as $T N F-\alpha$, cyclooxygenase-2 (COX-2) and interleukin-1- $\alpha(I L-1 \alpha)$. Low-intensity 633-nm LED irradiation resulted in very minor changes in the expression levels of these genes in the HaCaT cells (Fig. 4A), indicating that low intensity LED irradiation may not induce a skin inflammatory effect. High intensity 633-nm LED irradiation, however, significantly downregulated the levels of $C O X-2$ and $I L-1 \alpha$ (Fig. 4B). Notably, following $47.5 \mu \mathrm{W} / \mathrm{cm}^{2}$ LED 
A

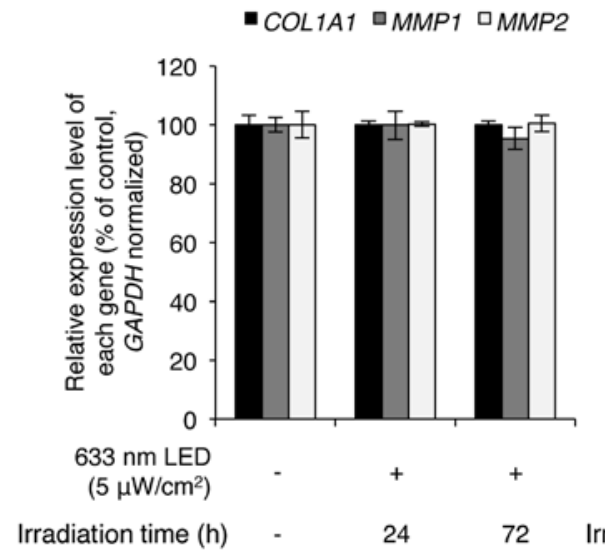

B

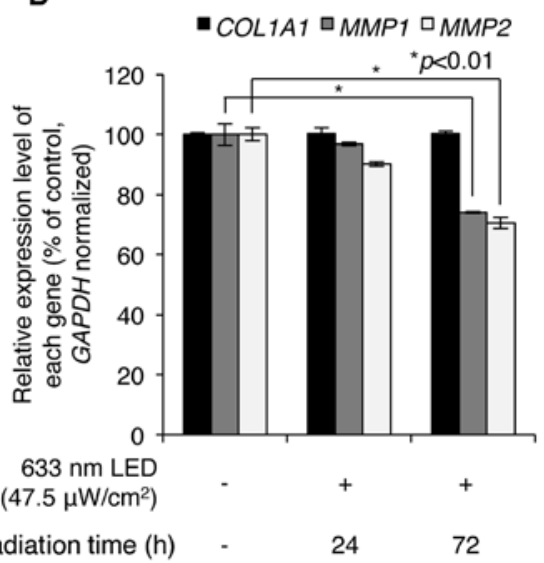

Figure 3. Irradiation with a 633-nm LED regulates the expression levels of collagen, type I, alpha 1 (COL1A1), matrix metalloproteinase (MMP)1 and $M M P 2$ in CCD986-sk human fibroblasts. (A) RT-qPCR analysis of the relative expression of COL1A1, MMP1 and MMP2 in CCD986-sk cells irradiated with low intensity $\left(5 \mu \mathrm{W} / \mathrm{cm}^{2}\right)$ LED for 24 and $72 \mathrm{~h}$. Values are presented as the level of each mRNA normalized to the GAPDH level. The data are representative of 3 independent experiments (means $\pm \mathrm{SD}$ ). (B) High intensity LED downregulates the expression levels of $M M P 1$ and $M M P 2$, but not those if COL1A1 in CCD986-sk cells. Cells were irradiated with $47.5 \mu \mathrm{W} / \mathrm{cm}^{2}$ LED for 24 and $72 \mathrm{~h}$, and subjected to RT-qPCR for COL1A1, MMP1 and MMP2 mRNAs. Values are presented as the level of each mRNA normalized to the GAPDH level. The data are representative of 3 independent experiments (means $\pm \mathrm{SD}$ ). "p $<0.01$ compared with controls (no treatment).

A

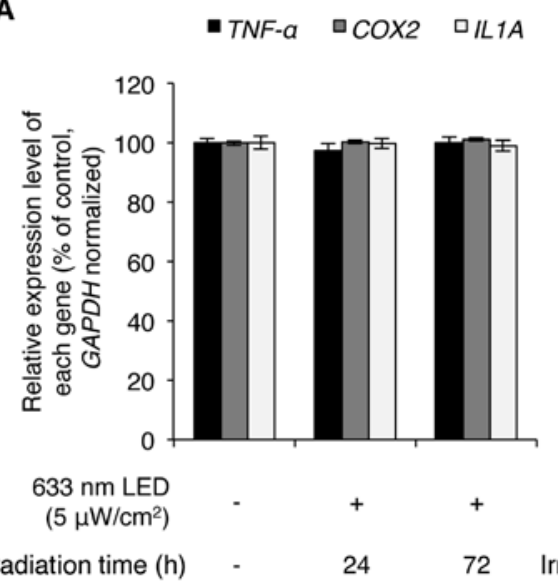

B

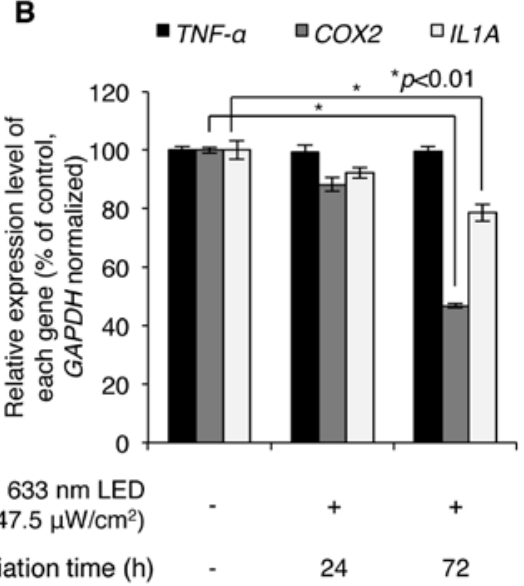

Figure 4. Irradiation with a 633-nm LED regulates the expression levels of tumor necrosis factor (TNF)- $\alpha$, cyclooxygenase-2 (COX-2) and interleukin (IL)-1 $\alpha$ in HaCaT human keratinocytes. (A) RT-qPCR analysis of $T N F-\alpha, C O X-2$ and $I L-1 \alpha$ expression in HaCaT cells irradiated with low intensity LED. HaCaT cells were irradiated with $5 \mu \mathrm{W} / \mathrm{cm}^{2}$ LED for 24 and $72 \mathrm{~h}$. Cells were collected and subjected to RNA extraction and cDNA synthesis. The expression level of each mRNA was analyzed by RT-qPCR using its specific primer. GAPDH was used as a reference gene. The data are representative of 3 independent experiments (means \pm SD). (B) High intensity LED downregulates the expression levels of $C O X-2$ and $I L-1 \alpha$, but not $T N F-\alpha$ in HaCaT cells. Cells were irradiated with $47.5 \mu \mathrm{W} / \mathrm{cm}^{2} \mathrm{LED}$ for 24 and $72 \mathrm{~h}$ and subjected to RT-qPCR for each mRNA using specific primers. Values are presented as the level of each mRNA normalized to the GAPDH level. The data are representative of 3 independent experiments (means $\pm \mathrm{SD}$ ). ${ }^{*} \mathrm{p}<0.01$ compared with controls (no treatment).

$(633 \mathrm{~nm})$ irradiation for $24 \mathrm{~h}$, the $C O X-2$ expression levels decreased to of $88.2 \pm 2.4 \%$ of the controls and the $I L-1 \alpha$ expression levels decreased to $92.3 \pm 1.8 \%$ of the control; following $72 \mathrm{~h}$ of irradiation, the expression levels of $C O X-2$ decreased to $46.8 \pm 0.8 \%$ of the controls and the $I L-1 \alpha$ expression levels decreased to $78.6 \pm 2.9 \%$ of the controls. Of note, the expression of $T N F$ - $\alpha$ was not altered by LED irradiation, indicating that the expression of $T N F-\alpha$ was not regulated under these LED-irradiating conditions. Overall, these results suggest that 633-nm LED irradiation has a potential anti-inflammatory effect on the skin.

LED irradiation promotes the proliferation of human keratinocytes. As described above, we found that 633-nm LED irradiation was not cytotoxic and slightly increased the viability of $\mathrm{HaCaT}$ human keratinocytes. We therefore evaluated the long-term effects of LED irradiation on the proliferation of $\mathrm{HaCaT}$ cells in culture for up to 14 days. Long-term irradiation with low $\left(5 \mu \mathrm{W} / \mathrm{cm}^{2}\right)$ and high $\left(47.5 \mu \mathrm{W} / \mathrm{cm}^{2}\right)$ intensity $633 \mathrm{~nm}$ LED for 14 days did not induce cytotoxicity, but continuously and moderately promoted cell viability (Fig. 5). Irradiation with 5 and $47.5 \mu \mathrm{W} / \mathrm{cm}^{2}$ LED at $633 \mathrm{~nm}$ resulted in cell proliferation rates of 102.4 and $106.4 \%$ of the controls, respectively, indicating that long-term LED irradiation at $633 \mathrm{~nm}$ does not induce any cytotoxic effects on keratinocytes.

Safety of LED irradiation on human skin tissue. We sought to confirm the safety of 633-nm LED irradiation with respect to 


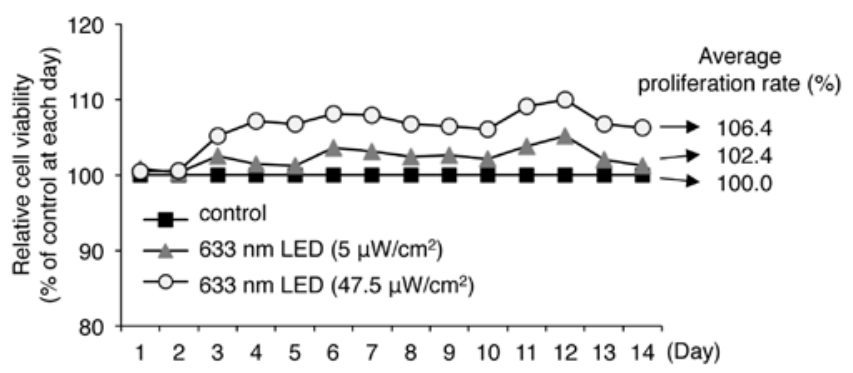

Figure 5. Irradiation with a 633-nm LED induces the proliferation of HaCaT human keratinocytes. HaCaT cells were grown under low $\left(5 \mu \mathrm{W} / \mathrm{cm}^{2}\right)$ and high $\left(47.5 \mu \mathrm{W} / \mathrm{cm}^{2}\right)$ intensity LED irradiation conditions for 14 days. Cell viability was determined by WST-1 assay each day. An average proliferation rate was presented as the mean value (\%) for all data of each experiment set.

the skin allergic reaction using human skin explants. The skin explants were obtained as full-thickness human skin biopsies from an abdominoplasty of a 45 -year-old Caucasian woman. The skin explants were subjected to 1 of 3 experimental conditions. The first group of samples served as the control explants $(n=9)$, which were not treated with any agents or exposed toLED irradiation. The second group of samples served as the positive control explants $(n=12)$, which were treated with the allergic response-inducing agents, DNCB and the
Dermatophagoides farinae body extract. The third group of samples served as the experimental explants $(\mathrm{n}=12)$, which were irradiated with low $\left(5 \mu \mathrm{W} / \mathrm{cm}^{2}\right)$ and high $\left(47.5 \mu \mathrm{W} / \mathrm{cm}^{2}\right)$ intensity LED at $633 \mathrm{~nm}$. The agents and LED irradiation were applied for 0,1 or 2 days. We first analyzed the general morphology of the explants by staining with Masson's trichrome, Goldner variant. As shown in Fig. 6, the batch irradiated with the low and high intensity 633-nm LED did not exhibit any changes in morphology on days 1 and 2, indicating that irradiation with a 633-nm LED does not induce any notable changes in skin tissue. Subsequently, we determined whether LED irradiation induces an allergic reaction in human skin by counting the number of CDla-positive Langerhans cells in the epidermis in each batch sample. Under allergy-inducing conditions, Langerhans cells migrate from the epidermis to the dermis, resulting in a decrease in the number of positive cells in the epidermis (16). As shown in Fig. 7, the positive control samples, which were treated with DNCB solution and Dermatophagoides farinae body extract for 1 or 2 days, showed a decrease in the number of CD1a-positive Langerhans cells in the epidermis compared to the control batches, indicating that these agents induce an allergic reaction. However, the experimental batches, which were exposed to low $\left(5 \mu \mathrm{W} / \mathrm{cm}^{2}\right)$ and high $\left(47.5 \mu \mathrm{W} / \mathrm{cm}^{2}\right)$ intensity 633-nm LED irradiation for 1 or 2 days, showed only slight differences in the number of CDla-positive Langerhans cells in the epidermis compared to the control batches (Fig. 7).
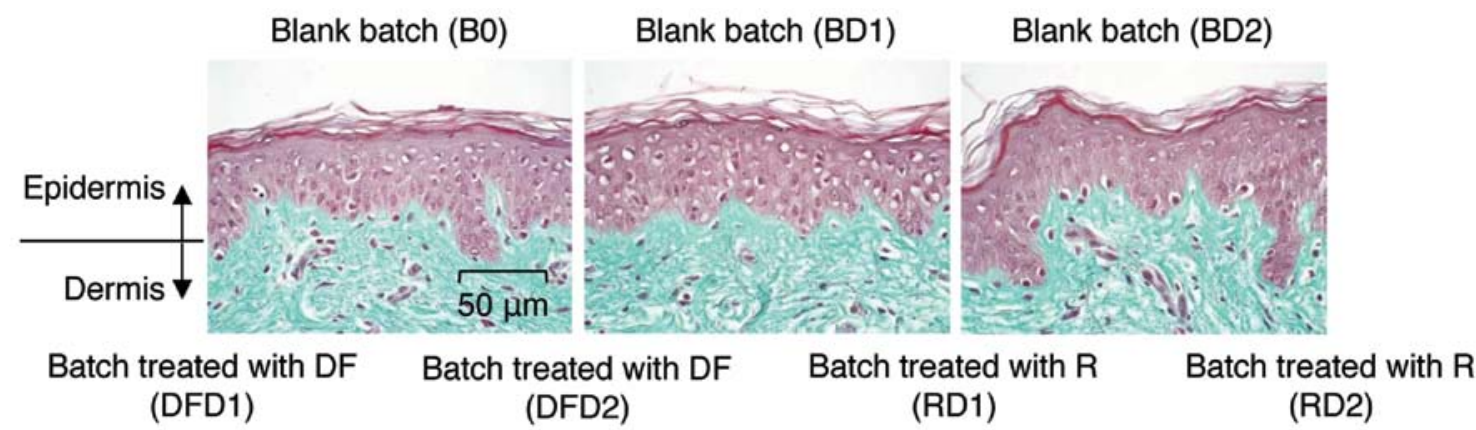

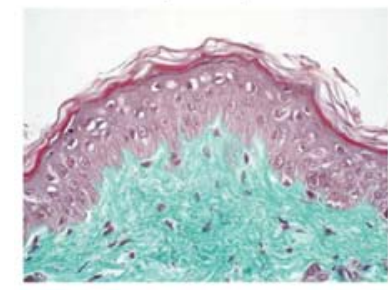

Batch treated with LL (LLD1)

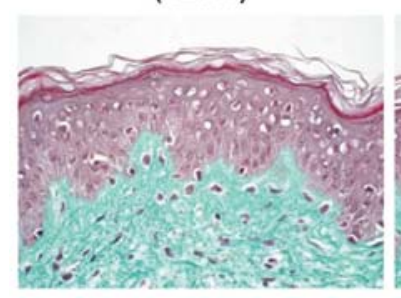

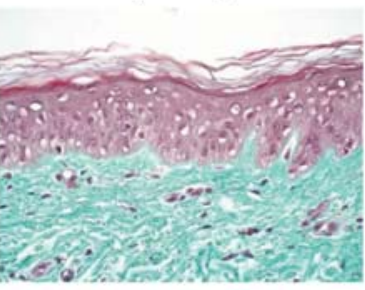

Batch treated with LL (LLD2)

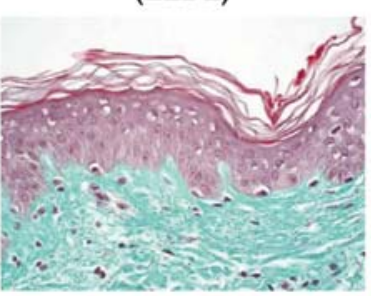

(RD1)

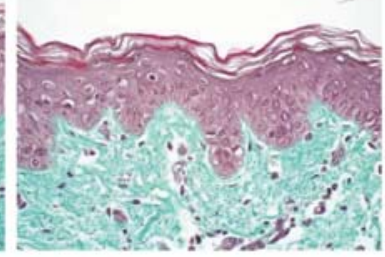

Batch treated with $\mathrm{LH}$ (LHD1)

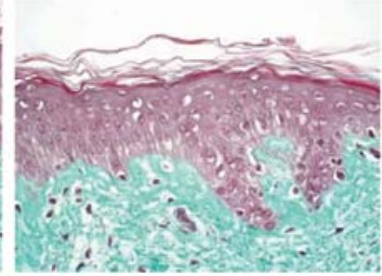

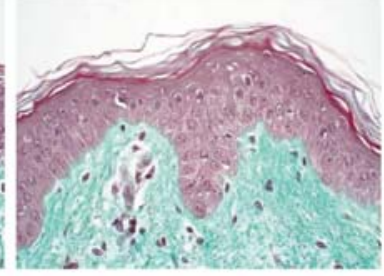

Batch treated with $\mathrm{LH}$ (LHD2)

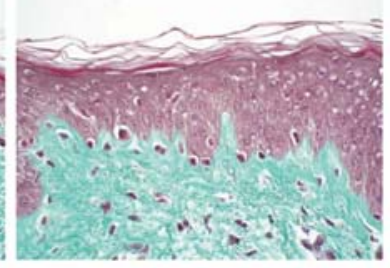

Figure 6. Tissue morphologies for the batches of human skin explants. One group of human tissue explants was treated with topical 1-chloro-2,4-dinitrobenzene (DNCB) solution or Dermatophagoides farinae body extract for 1 and 2 days. Another group of explants was irradiated with low $\left(5 \mu \mathrm{W} / \mathrm{cm}^{2}\right)$ or high $\left(47.5 \mu \mathrm{W} / \mathrm{cm}^{2}\right)$ intensity LED for 1 and 2 days. After treatment, the explants were fixed and sliced. General morphology was analyzed microscopically in paraffinized sections dyed with Masson's trichrome. B, blank batch; 0, control; D1, 1 day; D2, 2 days; DF, Dermatophagoides farinae body extract-treated batch; R, DCNB-treated batch; LL, low-intensity LED; LH, high-intensity LED. 


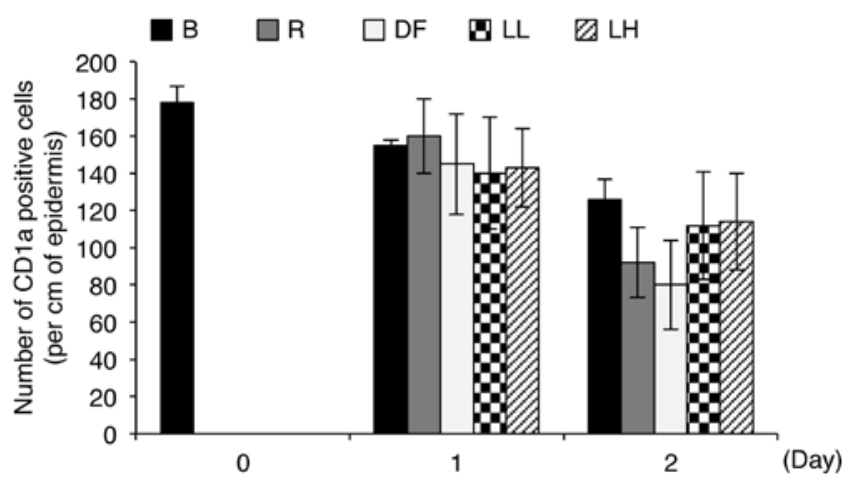

Figure 7. Irradiation with a 633-nm LED exerts a minimal effect on the activation of Langerhans cells in the epidermis of human skin explants. The 1-chloro2,4-dinitrobenzene (DNCB) solution and the Dermatophagoides farinae body extract were applied topically to each explant group for 1 and 2 days. Low $\left(5 \mu \mathrm{W} / \mathrm{cm}^{2}\right)$ and high $\left(47.55 \mu \mathrm{W} / \mathrm{cm}^{2}\right)$ intensity LED irradiation was applied to another group of explants for 1 and 2 days. The number of CD1a-positive Langerhans cells was determined using immunolabelling of paraffinized sections with an anti-CD1a antibody. The CD1a-positive cells were calculated lengthways for each explant, and the number was extrapolated to the epidermic length in centimeters. B, blank batch; R, DCNB-treated batch; DF, Dermatophagoides farinae body extract-treated batch; LL, low-intensity LED; LH, high-intensity LED.

In addition, the number of CD1a-positive Langerhans cells in the epidermis in the irradiated samples was not altered in an intensity-dependent manner (Fig. 7). Notably, the numbers of CD1a-positive Langerhans cells in the epidermis in the control batches and the batches irradiated with low and high intensity LED for 2 days were $126 \pm 11,112 \pm 29$ and $114 \pm 26$, respectively, whereas the numbers of the cells in the epidermis in the positive control batches were $92 \pm 19$ and $80 \pm 24$, respectively (Fig. 7). These results indicate that irradiation with a 633-nm LED does not induce allergic reactions in human skin explants.

\section{Discussion}

The present study examined the anti-aging effects of LED irradiation at a wavelength of $633 \mathrm{~nm}$ on human skin cells. Exposure to $5 \mu \mathrm{W} / \mathrm{cm}^{2}$ and $47.5 \mu \mathrm{W} / \mathrm{cm}^{2}$ irradiation from a 633-nm LED was non-cytotoxic and exerted a positive effect on skin strength and elasticity through the upregulation of procollagen type 1 molecules in human skin fibroblasts. The synthesis of collagen in the skin is regulated by transcriptional and post-translational mechanisms in fibroblasts $(17,18)$. The upregulation of COL1A1, which encodes the $\alpha 1$ chain of type 1 collagen, directly increases the synthesis of type 1 procollagen (17). In this study, we found that irradiation with a 633-nm LED did not increase the transcription of COL1A1, indicating that the observed LED irradiation-mediated increase in type 1 procollagen production is not a COL1A1 transcription-dependent mechanism. Rather, this effect occurs through another mechanism. The efficiency in chaperonemediated procollagen folding is also directly engaged in the level of procollagen synthesis in fibroblasts $(19,20)$. In addition, studies have identified the heat shock protein (HSP) 47 as a specific chaperone of procollagen and have demonstrated that the level of HSP47 is decreased in in old donor and senescent cells $(20,21)$. Furthermore, a previous study found that irra- diation with a toxic light source, such as ultraviolet B (UVB), significantly decreased the level of HSP47 (21). Therefore, the LED irradiation-mediated increase in procollagen production may be induced by an alteration in the levels of a procollagenspecific chaperone protein directly or indirectly.

The atrophy of collagen fibers in skin aging predominantly results from the increased expression of the degradative enzymes, $M M P 1$ and $M M P 2(22,23)$. Therefore, $M M P 1$ and $M M P 2$ are considered skin aging-related genes, and the overexpression of $M M P 1$ and $M M P 2$ genes has been found in aged/ photoaged skin in vivo (24). Thus, in this study, we examined the LED-mediated anti-aging effects by analyzing the expression levels of $M M P 1$ and $M M P 2$. We found that 633-nm LED irradiation decreased the expression of both of these genes. While low intensity LED did not markedly decrease the expression of these genes, exposure to $47.5 \mu \mathrm{W} / \mathrm{cm}^{2}$ of $633-\mathrm{nm}$ LED irradiation for 2 days (maximum dose used in this study) decreased the levels of $M M P 1$ and $M M P 2$ by 24 and $29 \%$, respectively. Indeed, MMPs are essential to epidermal (keratinocyte) differentiation and the prevention of wound scars, indicating that the excessive loss of MMPs yields rather harmful effects on skin integrity (25). In addition, such a loss in MMP expression induces keratinocyte hyperproliferation, which is one of the main characteristics of aged skin $(26,27)$. We also confirmed that long-term exposure to the maximum dose of 633-nm LED irradiation resulted in a moderate increase in the proliferation rate of keratinocytes for up to 14 days. Therefore, our data indicate that a decrease in $M M P 1$ and $M M P 2$ expression at such a moderate level may not be harmful to skin health.

Protection of the skin from inflammatory reaction is paramount. UV irradiation and allergen exposure may lead to acute and chronic inflammation of the skin. Accumulating evidence suggests that inflammation is causally linked to carcinogenesis and acts as a driving force in the premalignant and malignant transformation of cells. Indeed, in a mouse skin model, the topical application of the inflammation-inducing agent, 12-O-tetradecanoylphorbol-13-acetate (TPA), was shown to lead to papilloma formation in mice through the enhancement of the expression of $C O X-2$, which is a key enzyme in the inflammatory response (28). Based on this evidence, in this study, we examined the effects of 633-nm LED irradiation on skin inflammation by analyzing the expression levels of inflammation-related genes using an in vitro cell culture model and by examining the general morphological changes and allergic effects in an ex vivo human skin model. Our data indicated that the maximum dose of $633-\mathrm{nm}$ LED radiation decreased the expression levels of $C O X-2$ and $I L-1 \alpha$ by 53.2 and $21.4 \%$, respectively, compared to the controls. $C O X-2$ is a highly inducible enzyme that is involved in the production of a secondary mediator known to be triggered in many inflammatory states (29). $I L-1 \alpha$, which has been identified as a useful screening tool for skin irritation, initiates a signaling cascade involved in the inflammatory response $(30,31)$. Studies have demonstrated that both $I L-1 \alpha$ and $T N F-\alpha$ are key molecules that induce the expression of several cytokines, as well as $C O X-2$ (31,32). However, our study revealed that neither the minimum nor the maximum dose of 633-nm LED irradiation regulated the expression of $T N F-\alpha$, indicating that, although the level of $C O X-2$ and $I L-1 \alpha$ was downregulated by this irradiation, the $T N F-\alpha$-mediated inflammatory response was not regulated 
by this exposure. Notably, TNF- $\alpha$ expression is observed at very low levels in cultured keratinocytes and appears to play a lesser role in inflammation in vivo as compared to $I L-1 \alpha(33,34)$. Therefore, it is noteworthy that irradiation with a 633-nm LED does not induce a skin inflammatory response, but rather exerts an anti-inflammatory effect in vitro.

Since extrapolation from the in vitro experiments to the more relevant in vivo situation is difficult, we investigated the effects of a 633-nm LED irradiation on skin inflammation in human skin explant in ex vivo experiments. A total of 33 skin explants from a Caucasian woman were obtained, and the possibility of a skin allergic reaction following LED irradiation was examined. We found that both the minimum and the maximum dose of LED irradiation resulted in indistinguishable changes in the level of allergic response compared to the control human skin explants. Therefore, our data indicate that irradiation with a 633-nm LED does not induce skin inflammation in vitro or in vivo.

In conclusion, we demonstrated that 633-nm LED irradiation exerts an anti-aging and anti-wrinkle effect on human skin through the upregulation of type 1 procollagen and the downregulation of $M M P 1$ and $M M P 2$. We also confirmed that this irradiation is not cytotoxic and does not induce inflammatory effects in human skin using both an in vitro skin cell culture system and an ex vivo human skin explant system. In addition, this irradiation did not induce keratinocyte hyperproliferation. Taken together, these findings suggest that the irradiation of human skin using a 633-nm LED may prove useful for the prevention and treatment of skin aging and photodamageinduced aging, although the clinical significance of $633-\mathrm{nm}$ LED irradiation in vivo requires further investigation.

\section{References}

1. Farage MA, Miller KW, Elsner P and Maibach HI: Intrinsic and extrinsic factors in skin ageing: a review. Int J Cosmet Sci 30: 87-95, 2008.

2. Friedman O: Changes associated with the aging face. Facial Plast Surg Clin North Am 13: 371-380, 2005.

3. Bergfeld WF: The aging skin. Int J Fertil Womens Med 42: 57-66, 1997.

4. Sjerobabski-Masnec I and Situm M: Skin aging. Acta Clin Croat 49: 515-518, 2010.

5. Gelse K, Poschl E and Aigner T: Collagens - structure, function, and biosynthesis. Adv Drug Deliv Rev 55: 1531-1546, 2003.

6. Yin L, Morita A and Tsuji T: Skin aging induced by ultraviolet exposure and tobacco smoking: evidence from epidemiological and molecular studies. Photodermatol Photoimmunol Photomed 17: 178-183, 2001

7. Lee JH, Chung JH and Cho KH: The effects of epigallocatechin3 -gallate on extracellular matrix metabolism. J Dermatol Sci 40: 195-204, 2005.

8. Wang CC, Hui CY, Sue YM, Wong WR and Hong HS: Intense pulsed light for the treatment of refractory melasma in Asian persons. Dermatol Surg 30: 1196-1200, 2004.

9. Taylor M, Porter R and Gonzalez M: Intense pulsed light may improve inflammatory acne through TNF-alpha down-regulation. J Cosmet Laser Ther 16: 96-103, 2014.

10. Barolet D, Roberge CJ, Auger FA, Boucher A and Germain L: Regulation of skin collagen metabolism in vitro using a pulsed $660 \mathrm{~nm}$ LED light source: clinical correlation with a single-blinded study. J Invest Dermatol 129: 2751-2759, 2009.

11. Lee SY, Park KH, Choi JW, et al: A prospective, randomized, placebo-controlled, double-blinded, and split-face clinical study on LED phototherapy for skin rejuvenation: clinical, profilometric, histologic, ultrastructural, and biochemical evaluations and comparison of three different treatment settings. J Photochem Photobiol B 88: 51-67, 2007.
12. Weiss RA, McDaniel DH, Geronemus RG and Weiss MA: Clinical trial of a novel non-thermal LED array for reversal of photoaging: clinical, histologic, and surface profilometric results. Lasers Surg Med 36: 85-91, 2005.

13. Russell BA, Kellett N and Reilly LR: A study to determine the efficacy of combination LED light therapy $(633 \mathrm{~nm}$ and $830 \mathrm{~nm}$ ) in facial skin rejuvenation. J Cosmet Laser Ther 7: 196-200, 2005.

14. Tian YS, Kim NH and Lee AY: Antiphotoaging effects of light-emitting diode irradiation on narrow-band ultraviolet B-exposed cultured human skin cells. Dermatol Surg 38: 1695-1703, 2012.

15. Goldberg DJ, Amin S, Russell BA, Phelps R, Kellett N and Reilly LA: Combined 633-nm and 830-nm led treatment of photoaging skin. J Drugs Dermatol 5: 748-753, 2006.

16. Ouwehand K, Scheper RJ, de Gruijl TD and Gibbs S: Epidermis-to-dermis migration of immature Langerhans cells upon topical irritant exposure is dependent on CCL2 and CCL5. Eur J Immunol 40: 2026-2034, 2010.

17. Grant ME and Ayad S: The collagens of skin: structure and assembly. Biochem Soc Trans 16: 663-666, 1988.

18. Cutroneo KR: How is type I procollagen synthesis regulated at the gene level during tissue fibrosis. J Cell Biochem 90: 1-5, 2003.

19. Lamande SR and Bateman JF: Procollagen folding and assembly: the role of endoplasmic reticulum enzymes and molecular chaperones. Semin Cell Dev Biol 10: 455-464, 1999.

20. Ishida $\mathrm{Y}$ and Nagata K: Hsp47 as a collagen-specific molecular chaperone. Methods Enzymol 499: 167-182, 2011.

21. Nizard C, Noblesse E, Boisde C, et al: Heat shock protein 47 expression in aged normal human fibroblasts: modulation by Salix alba extract. Ann NY Acad Sci 1019: 223-227, 2004.

22. Khorramizadeh MR, Tredget EE, Telasky C, Shen Q and Ghahary A: Aging differentially modulates the expression of collagen and collagenase in dermal fibroblasts. Mol Cell Biochem 194: 99-108, 1999.

23. Millis AJ, Hoyle M, McCue HM and Martini H: Differential expression of metalloproteinase and tissue inhibitor of metalloproteinase genes in aged human fibroblasts. Exp Cell Res 201: 373-379, 1992.

24. Quan T, Qin Z, Xia W, Shao Y, Voorhees JJ and Fisher GJ: Matrix-degrading metalloproteinases in photoaging. J Investig Dermatol Symp Proc 14: 20-24, 2009.

25. Philips N, Auler S, Hugo R and Gonzalez S: Beneficial regulation of matrix metalloproteinases for skin health. Enzyme Res 2011: 427285, 2011.

26. Philips N, Tuason M, Chang T, Lin Y, Tahir M and Rodriguez SG: Differential effects of ceramide on cell viability and extracellular matrix remodeling in keratinocytes and fibroblasts. Skin Pharmacol Physiol 22: 151-157, 2009.

27. Buisson-Legendre N, Emonard H, Bernard P and Hornebeck W: Relationship between cell-associated matrix metalloproteinase 9 and psoriatic keratinocyte growth. J Invest Dermatol 115: 213-218, 2000.

28. Seo HJ, Park KK, Han SS, et al: Inhibitory effects of the standardized extract (DA-9601) of Artemisia asiatica Nakai on phorbol ester-induced ornithine decarboxylase activity, papilloma formation, cyclooxygenase-2 expression, inducible nitric oxide synthase expression and nuclear transcription factor kappa B activation in mouse skin. Int J Cancer 100: 456-462, 2002.

29. Dubois RN, Abramson SB, Crofford L, et al: Cyclooxygenase in biology and disease. FASEB J 12: 1063-1073, 1998.

30. Wilmer JL, Burleson FG, Kayama F, Kanno J and Luster MI: Cytokine induction in human epidermal keratinocytes exposed to contact irritants and its relation to chemical-induced inflammation in mouse skin. J Invest Dermatol 102: 915-922, 1994.

31. Galley HF and Webster NR: The immuno-inflammatory cascade. Br J Anaesth 77: 11-16, 1996.

32. Williams IR and Kupper TS: Immunity at the surface: homeostatic mechanisms of the skin immune system. Life Sci 58: 1485-1507, 1996.

33. Kock A, Schwarz T, Kirnbauer R, et al: Human keratinocytes are a source for tumor necrosis factor alpha: evidence for synthesis and release upon stimulation with endotoxin or ultraviolet light. J Exp Med 172: 1609-1614, 1990.

34. Newby CS, Barr RM, Greaves MW and Mallet AI: Cytokine release and cytotoxicity in human keratinocytes and fibroblasts induced by phenols and sodium dodecyl sulfate. J Invest Dermatol 115: 292-298, 2000. 